\title{
Peroxiredoxin I participates in the protection of reactive oxygen species-mediated cellular senescence
}

\author{
Young-Ho Park ${ }^{2,3,7, \#}$, Hyun-Sun Kim ${ }^{1, \#}$, Jong-Hee Lee, ${ }^{2, \#}$, Seon-A Choi ${ }^{2,3}$, Jin-Man Kim ${ }^{4}$, Goo Taeg Oh ${ }^{5}$, Sang Won Kang , \\ Sun-Uk Kim ${ }^{2,3,7, *}$ \& Dae-Yeul Yu ${ }^{1,7, *}$ \\ ${ }^{1}$ Disease Model Research Laboratory, Genome Editing Research Center, Korea Research Institute of Bioscience and Biotechnology, Daejeon \\ 34141, ${ }^{2}$ National Primate Research Center, ${ }^{3}$ Futuristic Animal Resource \& Research Center, Korea Research Institute of Bioscience and \\ Biotechnology, Cheongju 28116, ${ }^{4}$ College of Medicine, Chungnam National University, Daejeon $35015,{ }^{5}$ Department of Life Sciences and \\ Immune and Vascular Cell Network Research Center, Ewha Womans University, Seoul 03760, ${ }^{6}$ Department of Life Sciences and Cell \\ Homeostasis Research Center, Ewha Womans University, Seoul 03760, ${ }^{7}$ Department of Functional Genomics, University of Science and \\ Technology, Daejeon 34113, Korea
}

Peroxiredoxin I (Prx I) plays an important role as a reactive oxygen species (ROS) scavenger in protecting and maintaining cellular homeostasis; however, the underlying mechanisms are not well understood. Here, we identified a critical role of Prx I in protecting cells against ROS-mediated cellular senescence by suppression of $\mathrm{p}^{16^{\mathrm{INK4a}}}$ expression. Compared to wild-type mouse embryonic fibroblasts (WT-MEFs), Prx $\mathrm{I}^{-/-}$MEFs exhibited senescence-associated phenotypes. Moreover, the aged Prx $\mathrm{I}^{-1-}$ mice showed an increased number of cells with senescence associated- $\beta$-galactosidase (SA- $\beta$-gal) activity in a variety of tissues. Increased ROS levels and SA- $\beta$-gal activity, and reduction of chemical antioxidant in $\operatorname{Prx} \mathrm{I}^{-1-}$ MEF further supported an essential role of Prx I peroxidase activity in cellular senescence that is mediated by oxidative stress. The up-regulation of $\mathrm{p} 16^{\mathrm{INK4a}}$ expression in Prx $\mathrm{I}^{-/-}$and suppression by overexpression of Prx I indicate that Prx I possibly modulate cellular senescence through ROS/p16 ${ }^{\text {INK4a }}$ pathway. [BMB Reports 2017; 50(10): 528-533]

\section{INTRODUCTION}

Cellular senescence is defined as a proliferative arrest of a cell, accompanied by phenotypic and physiological changes including enlarged and flattened cell morphology and the appearance of SA- $\beta$-gal activity at $\mathrm{pH} 6.0$ (1), which is caused

${ }^{*}$ Corresponding authors. Sun-Uk Kim, Tel: +82-43-240-6321; Fax: +82-43-240-6309; E-mail: sunuk@kribb.re.kr; Dae-Yeul Yu, Tel: +8242-860-4422; Fax: +82-42-860-4609; E-mail: dyyu10@kribb.re.kr ${ }^{\#}$ These authors contributed equally to this work.

https://doi.org/10.5483/BMBRep.2017.50.10.121

Received 7 July 2017, Revised 31 July 2017, Accepted 12 September 2017

Keywords: Antioxidant enzyme, Cellular senescence, Oxidative stress, p16 ${ }^{\text {INK4a }}$, Peroxiredoxin by a variety of cellular stressors, such as active oncogenes, DNA damage, and oxidative overload (2-4). In particular, oxidative stress is the most common factor that induces cellular senescence in a variety of mammalian cells, including fibroblasts, keratinocytes, and cancer cells (5-7). Excessive accumulation of intracellular ROS leads to an increase in cellular senescence (8) through the activation of cell cycle inhibitors, $\mathrm{p} 16^{\text {INK4a }}$ and p2 $1^{\text {WAF1/CIP }}(9,10)$. Despite the increasing number of studies that have proposed the importance of redox homeostasis in the regulation of cellular aging, the characterization of major antioxidants governing cellular senescence and their underlying mechanisms have not yet been fully elucidated.

Peroxiredoxin (Prx) is a family of antioxidant enzymes that contain thiol groups, and their primary role is closely related to alleviation of cellular oxidative stress (11). In addition, Prxs are frequently involved in oxidative damage-associated diseases, tumorigenesis, and degenerative disorders such as Parkinson's and Alzheimer's disease (12-14). Previous reports have revealed that the function of Prx II is associated with anti-aging activity in mouse embryonic fibroblasts (MEFs) and hippocampal neurons, as evidenced by accelerated cellular senescence and age-related cognitive failure in Prx $\|^{-l-}$ MEFs and mice, respectively (15). Prx I is the most abundant and ubiquitously distributed of the six Prx members (I-VI) and is mainly characterized as a regulator of cell proliferation and differentiation (16). Similar to Prx II, the augmented expression of Prx I is often found in a variety of age-related diseases including cancers and neurodegenerative diseases (17). Despite the high similarity in sequence and function between Prx I and Prx II, the functional role of Prx I in senescence has not yet been clearly defined.

In this study, we demonstrated that a null mutation of $\operatorname{Prx}$ I led to the induction and accumulation of cellular senescence. In vitro Prx $\mathrm{I}^{-1-}$ MEFs displayed senescent phenotypes, including an enlarged and flattened morphology and high SA- $\beta$-gal activity, which may have been mediated by the 
elevation of ROS and $\mathrm{p} 16^{\text {INK4a }}$ levels. Increased SA- $\beta$-gal activity in aged $\operatorname{Prx~I^{-1-}}$ mice further supported the in vivo role of Prx I in cellular senescence. These findings will provide compelling evidence for the role of oxidative stress as a potential inducer of aging and increase the understanding of the molecular mechanism(s) underlying cellular senescence.

\section{RESULTS}

\section{Prx I-deficient MEFs exhibit senescence-like morphology changes and retarded cell proliferation}

Primary MEFs were prepared from 13.5 day-old embryonic fetuses after natural mating between $\operatorname{Prx~I}^{+/-}$male and female mice, and were then genotyped and analyzed by western blotting analysis of Prx I. Compared to wild type (WT), expression of Prx I was decreased by approximately half in Prx $\mathrm{I}^{+--}$and completely disappeared and $\operatorname{Prx} \mathrm{I}^{-1}$ MEFs, respectively (Fig. 1A). To investigate the functional role of $\operatorname{Prx} I$ in cellular senescence, WT and $\operatorname{Prx} \mathrm{I}^{--}$MEFs were observed under an inverted microscope and subjected to flow cytometry to examine morphological and cell size changes, the characteristic features of senescence. Microscopic observation revealed that Prx I ${ }^{-l-}$ MEFs were larger and flatter than WT MEFs (Fig. 1B). Significant increases in the relative cell size of $\operatorname{Prx} \mathrm{I}^{- \text {- }}$
A

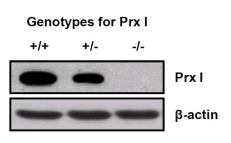

C
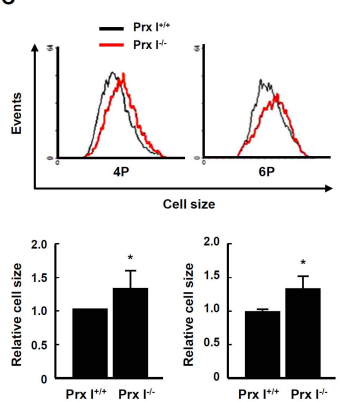

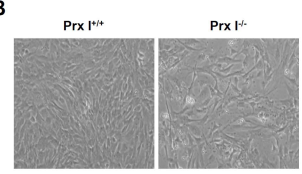

D

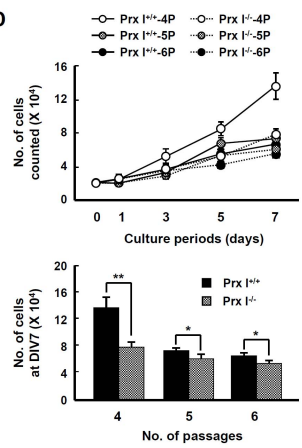

Fig. 1. Prx $\mathrm{I}^{-1-} \mathrm{MEFs}$ show persistent growth arrest and induce senescence-associated phenotypic changes. (A) MEFs derived from different Prx I genotypes were generated and maintained by a defined $3 \mathrm{~T} 3$ protocol. (B) Prx I $\mathrm{I}^{+/ 9}$ or Prx $\mathrm{I}^{-1-}$ MEFs images were captured at 4 passage under a differential interference contrast (DIC) microscopy. (C) Cell sizes of the indicated MEFs were assessed by measuring forward light scatter (FSC) via flow cytometry. 4P, 4 passage; 6P, 6 passage. Data represent Mean \pm SD $(n=3)$. *P $<0.05$. (D) The population doubling level was calculated for $\operatorname{Prx} \mathrm{I}^{+/+}$or $\operatorname{Prx~\mathrm {I}^{-/-}}$ MEFs at each passage every 2 days (upper panel) and cells were counted at 7 days in vitro (DIV) (lower panel). Data represent Mean \pm SD $(n=3)$. $* P<$ $0.05, * * P<0.01$.
MEFs were detected by flow cytometry analysis (Fig. 1C). In addition, cell proliferation was greatly reduced in $\operatorname{Prx~I^{-1-}}$ MEFs compared to WT cells regardless of passage number (passage number 4-6) (Fig. 1D). These results indicate that Prx I plays an important role in premature senescence, as revealed by the flattened cell morphology, reduced cell proliferation, and enlarged cell size after loss of Prx I expression.

\section{Induction of cellular senescence by loss of Prx I}

Since Prx $\mathrm{I}^{-1-}$ MEFs showed similar phenotypic changes as cells undergoing senescence, we evaluated whether $\operatorname{Prx~I^{-1-}}$ MEFs also exhibit SA- $\beta$-gal activity, an established hallmark of cellular senescence (Fig. 2A). Prx I ${ }^{-1-}$ MEFs had significantly increased SA- $\beta$-gal activity compared to Prx I ${ }^{+/+}$MEFs (Fig. $2 B)$. The quantified levels of SA- $\beta$-gal staining revealed that the frequency of positive cells was higher in cells without Prx I expression (Fig. 2C). Increased SA- $\beta$-gal activity was correlated with the passage number of cells, but this is probably mediated by spontaneous senescence in primary cell culture. We next set out to evaluate the in vivo functions of $\operatorname{Prx} I$ in cellular senescence by assessing SA- $\beta$-gal activity in various tissues and organs from $\operatorname{Prx} \mathrm{I}^{-1-}$ mice at 15 months of age. Consistent with the results from primary cell culture, SA- $\beta$-gal activity was observed only in the aged Prx I-null mouse (Fig. 2D), which further supports the role of Prx I in the aging process in vivo.
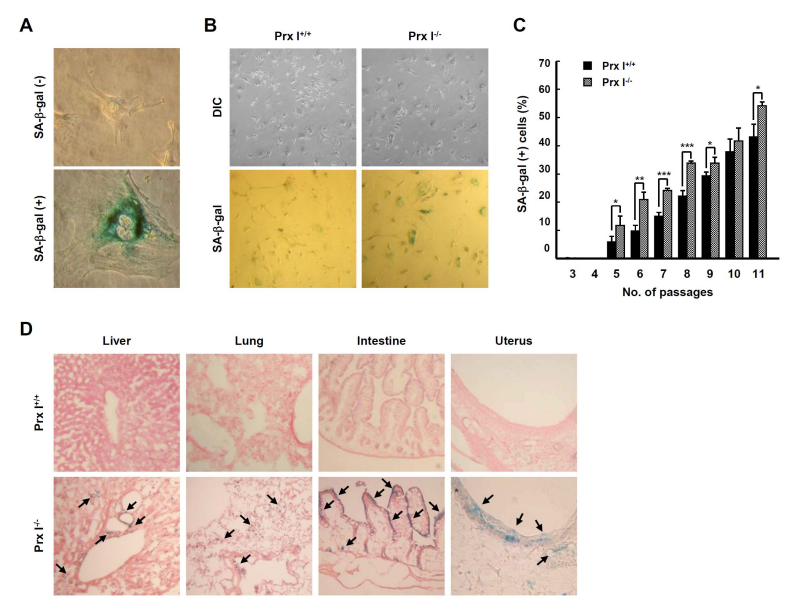

Fig. 2. Prx I deletion induceds cellular senescence both in vitro and in vivo. (A) Representative SA- $\beta$-gal staining images of earlyand late-passage Prx I ${ }^{+/+}$MEFs were shown. (B) Representative images of $\operatorname{Prx~I^{+/+}}$ and Prx $\mathrm{I}^{-1-}$ MEFs stained for SA- $\beta$-gal at 8 passage. (C) $\operatorname{Prx} \mathrm{I}^{+/+}$and $\operatorname{Prx} \mathrm{I}^{-/-}$MEFs were stained for SA- $\beta$-gal at each passage from 3 to 11 . SA- $\beta$-gal positive cells were counted in at least 10 fields from triplicate plates. Data represent Mean $\pm \mathrm{SD}(n=3)$. ${ }^{*} \mathrm{P}<0.05, * * \mathrm{P}<0.01, * * * \mathrm{P}<0.001$. (D) The Liver, the lung, the intestine, and the uterus of $\operatorname{Prx~I^{-1-}}$ mice were examined by SA- $\beta$-gal staining and compared to those of the $\operatorname{Prx~I^{+/+}}$ mice. Black arrows indicate that SA- $\beta$-gal positive cells. 


\section{Prx I regulates ROS-induced cellular senescence}

The induction of cellular senescence in primary cells is triggered by the accumulation of ROS (18). Based on previous studies, we hypothesized that Prx I deletion may generate oxidative stress, thereby inducing senescence in $\operatorname{Prx} \mathrm{I}^{-/-}$ MEFs. To address this question, we examined intracellular ROS levels, an indicator of oxidative stress, by staining MEFs with $\mathrm{CM}-\mathrm{H}_{2}$ DCFDA. Flow cytometric and immunocytochemical analysis revealed a significant increase $(\sim 2$-fold) in ROS levels in $\operatorname{Prx} \mathrm{I}^{-/-}$MEFs compared to Prx $\mathrm{I}^{+/+}$MEFs, implicating the important role of Prx I expression on oxidative stress (Fig. 3A and $\mathrm{B})$. Given the apparent regulation of ROS levels by Prx I expression, we blocked oxidative stress with $\mathrm{N}$-acetyl-L-cysteine (NAC), a chemical antioxidant. The intention was to further demonstrate that elevated ROS levels induced by loss of Prx I correlated with induced cellular senescence in the presence of $\mathrm{H}_{2} \mathrm{O}_{2}$ for short- (days in vitro, DIV3) or long-term treatment (DIV5). Prx $\mathrm{I}^{-1-}$ MEFs displayed a higher frequency of SA- $\beta$-gal-positive senescent cells than $\operatorname{Prx} \mathrm{I}^{+/+}$MEFs after induction of oxidative stress with $\mathrm{H}_{2} \mathrm{O}_{2}$ treatment, suggesting the involvement of $\operatorname{Prx} \mathrm{I}$ in the ROS scavenging system (Fig. 3C). The reduction of SA- $\beta$-gal-positive cells in Prx I ${ }^{-/-}$MEFs was comparable with $\operatorname{Prx} \mathrm{I}^{+/+} \mathrm{MEFs}$ upon NAC-induced oxidative stress blocking on DIV3, whereas it had little effect on DIV5.

Prx I suppresses cellular senescence via p16 ${ }^{\text {INK4a }}$ expression Previous studies suggested that cell cycle regulators, such as $\mathrm{p} 16^{\mathrm{INK} 4 \mathrm{a}}$ and p2 $1^{\text {WAF1/Cip1 }}$, are highly associated with senescence induction in mouse and human cultured cells (19). Therefore, we examined whether Prx I regulates cell cycle regulators in the induction of cellular senescence to explore the underlying
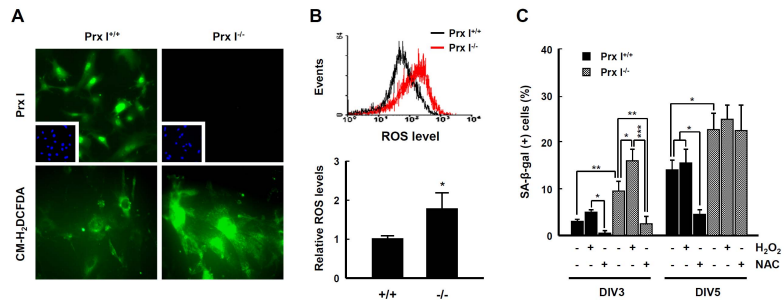

Fig. 3. Involvement of ROS in Prx I-induced cellular senescence. (A) Expression level of Prx I was examined with immunocytochemistry (ICC) in MEFs (upper panel). Images were counterstained with DAPI. ROS production was detected by the fluorescent CM-H2DCFDA using fluorescence microscopy (lower panel). (B) Intracellular ROS levels were analyzed by flow cytometry (upper panel). Data represent Mean \pm SD $(n=3)$. ${ }^{* P}<0.05$. (lower panel). (C) The percentage of cells positively stained for the SA$\beta$-gal activity in MEFs were pre-treated with presence or absence of either $5 \mathrm{mM} \mathrm{NAC}$ or $20 \mu \mathrm{M} \mathrm{H}_{2} \mathrm{O}_{2}$ at DIV 3 and 5. SA- $\beta$-gal positive cells were counted in at least 10 fields from triplicate plates. Data represent Mean $\pm \mathrm{SD}(n=3)$. ${ }^{* P}<0.05, * * P<$ $0.01, * * * P<0.001$. molecular mechanisms more closely. We showed that $\mathrm{p} 16^{\mathrm{INK} 4 \mathrm{a}}$ expression was significantly increased but that there was a little effect on p21 $1^{\text {WAF1/Cip1 }}$ or cyclin D1 after Prx I deletion with the progression of cell passage (Fig. $4 \mathrm{~A}$ and B). Moreover, expression of proliferating cell nuclear antigen (PCNA), an important factor related to proliferation, was inversely correlated with $\mathrm{p} 16^{\mathrm{INK} 4 \mathrm{a}}$ expression (Fig. 4A). To further confirm that upregulation of $\mathrm{p}^{16^{\mathrm{INK} 4 a}}$ expression in Prx $\mathrm{I}^{-/-}$MEFs was caused by Prx I deficiency, we re-introduced Prx I using adenoviral vectors. As shown in Fig. 4C, the expression of p16 $6^{\text {INK4a }}$ was downregulated by the exogenous induction of Prx I in a dose-dependent manner. Taken together, these results suggest that $\operatorname{Prx} I$ promotes cellular senescence by downregulating p16 ${ }^{\mathrm{INK} 4 \mathrm{a}}$ expression (Fig. 4D).

\section{DISCUSSION}

An increasing number of studies have documented that an increase in oxidative stress contributes to cellular senescence and that ROS play a critical role in aging that is induced by oxidative damage $(5,6,8)$. However, there are many unanswered questions regarding this relationship, including how ROS contribute to senescence induction and what the role of antioxidant enzymes are in age-related diseases. Previous studies from our and other laboratories indicated that inhibition of antioxidant enzymes such as superoxide dismutase 1 (SOD1), glutathione peroxidase $1(\mathrm{Gpx} 1)$, thioredoxin reductase 1 (TrxR1), or Prx II promotes stress-induced premature senescence in human and mouse fibroblasts (15, 20-23). These studies implied that the loss of the ability to scavenge ROS

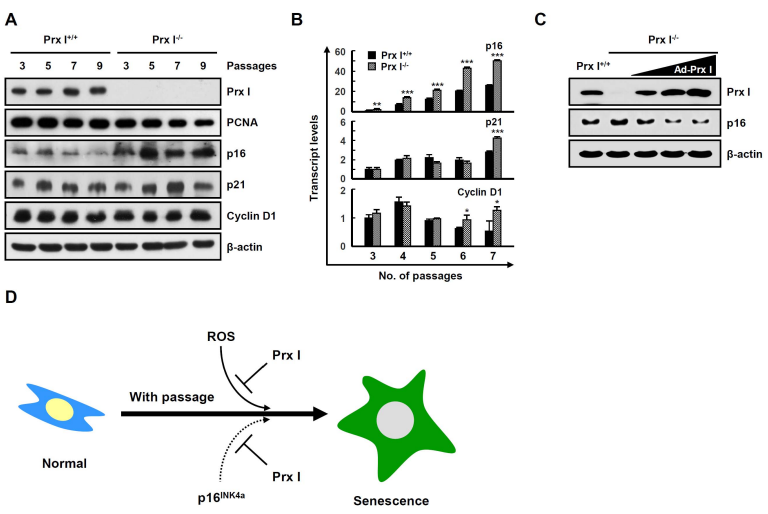

Fig. 4. Prx I deficiency leads to up-regulation of $\mathrm{p} 16^{\mathrm{INK} 4 \mathrm{a}}$ in MEFs. (A) Western blot analysis of Prx I, PCNA, p16 ${ }^{\text {INK4a }}, \mathrm{p} 21^{\text {WAF1/Cip1 }}$, Cyclin D1, and $\beta$-actin in MEFs at each passage. (B) mRNÁ expressions were analyzed by quantitative Real-time PCR in MEFs from WT and $\operatorname{Prx} \mathrm{I}^{-1-}$ for 3 to 7 passages. (C) Prx $\mathrm{I}^{-1-}$ MEFs were infected with recombinant adenovirus expressing human Prx $\mathrm{I}$ in a dose-dependent manner. Prx I and p16 ${ }^{\text {INK4a }}$ expressions were assessed by western blot using cell extracts. (D) Schematic illustration of essential role of $\operatorname{Prx}$ I regulate ROS/p16 ${ }^{\text {INK4a }}$ expression during cellular senescence by serial passage. 
during senescence was generally attributed to a decrease in the activity of antioxidant enzymes.

Prx I is known to play an important role in protecting against oxidative stress. Prx $\mathrm{I}^{-1-}$ mice showed increased oxidative damage to both DNA and protein (24). Consistent with these studies, our results demonstrate that the presence of senescent cells in Prx I ${ }^{-/-}$MEFs is highly associated with increased ROS levels, indicating that Prx I protects cells from oxidative damage by scavenging ROS (Fig. 3). In addition, we showed that the inhibitory effect of antioxidant NAC on cellular senescence were continuously detected in wild type MEFs regardless of culture periods, whereas it was not observed in Prx $\mathrm{I}^{-1-}$ MEFs cultured in long periods (Fig. 3C), indicating that different mechanisms might be involved in the cellular senescence induced by the loss of $\operatorname{Prx} \mathrm{I}$, oxidative stress independent senescence. Furthermore, our data clearly show that Prx I suppresses cellular senescence by regulating p16 1 INK4a $^{\text {IN }}$ expression (Fig. 4). Although it has been reported that ROS induces $\mathrm{p} 16^{\mathrm{INK} 4 \mathrm{a}}$ expression (25), the physiological significance and the mechanisms underlying Prx I function remain to be elucidated. Therefore, our findings may provide new regulatory mechanisms of Prx I in inhibiting senescence through the regulation of the ROS-p16 $6^{\text {INK4a }}$ expression. However, we still cannot rule out other regulatory mechanisms involved in $\operatorname{Prx}$ I-mediated senescence. Recently, it was reported that Prx I play a pivotal role in redox-regulated senescence by regulating p38 MAPK activity via modulating two p38 MAPK phosphatases, MAP kinase phosphatase 1 (MKP-1) and MKP-5 (26). It is possible that the concerted action of diverse regulatory mechanisms yield maximal consequences of $\operatorname{Prx} \mathrm{I}$ in the modulation of senescence induced by oxidative stress.

Response to senescence are widely recognized as a barrier against tumorigenesis $(18,27,28)$; however, senescence and tumorigenesis are positively linked $(29,30)$, suggesting that senescence might precede and/or sustain tumorigenesis. For instance, increased expression of $\mathrm{p} 16^{\mathrm{INK} 4 \mathrm{a}}$ has also been detected in several tumors (31), and activated oncogenes such as Ras or Myc are able to induce senescence and tumorigenesis simultaneously $(32,33)$. It is likely that the senescence triggered by oncogenic activation plays an important role as a natural physiological response to tumor development. $\operatorname{Prx} I$ is frequently elevated in various human cancers and is used as a potential prognostic marker. Recently, both our group and the Neumann group demonstrated that $\operatorname{Prx~I^{-1-}}$ mice have an increase likelihood of developing a tumor by activating oncogenic Ras $(34,35)$. As shown in Supplementary Fig. 1, loss of Prx I induced cellular senescence with slow cell proliferation in the early passage (before passage 15). However, $\operatorname{Prx} \mathrm{I}^{-1-}$ MEFs escaped senescence and grew rapidly and maintained high proliferation rate after 15 passages. Finally, $\operatorname{Prx~I}^{-1-}$ MEFs acquired immortalized features with uncontrolled division at early passage compared to primary MEFs $\left(15^{\text {th }}\right.$ passage vs. $20^{\text {th }}$ passage). Therefore, it is possible that promotion of senescence by the absence of Prx I activates tumorigenesis.
Further studies are required to fully understand how cellular senescence that is induced by Prx I affects tumorigenesis. This relationship could explain the dramatically increased incidence of cancer with advanced age. In conclusion, this study showed, for the first time, the functional role of Prx I as a novel regulator in cellular senescence.

\section{MATERIALS AND METHODS}

\section{Preparation of the MEFs}

Primary MEFs were prepared from 13.5 days post-coitum fetuses after natural mating between $\operatorname{Prx~I}^{+/-}$male and female mice as previously described (15). Wild-type (WT) and Prx $1^{-1-}$ MEFs were cultured in Dulbecco's modified Eagle medium (DMEM; Gibco), supplemented with 200 unit/ml penicillin-G-sodium, $100 \mu \mathrm{g} / \mathrm{ml}$ streptomycin (Sigma-Aldrich), $4 \mathrm{mM}$ L-glutamine and $10 \%$ fetal bovine serum (FBS; Hyclone).

\section{Cell proliferation assay}

MEFs were seeded at a density of $2 \times 10^{4}$ of cells in a 6-well plate, sampled by trypsinization, and stained by trypan blue dye. Subsequently, the cells were mounted onto a haematocytometer, and the cell number was counted under inverted microscope (Olympus).

\section{SA- $\beta$-gal activity staining}

SA- $\beta$-gal activity staining was performed using 5-bromo-4chloro-3-indolyl- $\beta$-D-galactosidase (X-gal) according to the manufacturer's instructions (Sigma-Aldrich). Quantification of SA- $\beta$-gal-positive cells was obtained by counting five random fields per dish and assessing the percentage.

\section{Measurement of intracellular ROS levels}

Intracellular ROS generation was assessed with an 5,6chloromethyl-2', $7^{\prime}$-dichlorodihydrofluorescein diacetate (CM$\mathrm{H}_{2}$ DCFDA; Invitrogen), a ROS indicator. Exponentially growing MEFs were incubated with $5 \mu \mathrm{M} \mathrm{CM}-\mathrm{H} 2 \mathrm{DCFDA}$ at $37^{\circ} \mathrm{C}$ for 15 min and washed twice with PBS by centrifugation at $200 \times$ $\mathrm{g}$ for $5 \mathrm{~min}$. The cells were resuspended with PBS and analyzed by flow cytometry on a FACSCalibur instrument (BD Biosciences).

\section{Chemical treatment}

Hydrogen peroxide $\left(\mathrm{H}_{2} \mathrm{O}_{2}\right.$; Sigma-Aldrich) previously diluted with sterile PBS was added to cell cultures at $20 \mu \mathrm{M}$ in growth media. Antioxidant treatments with $5 \mathrm{mM} \mathrm{N}$-acetyl-L-cysteine (NAC; Sigma-Aldrich) were performed $30 \mathrm{~min}$ before the addition of $\mathrm{H}_{2} \mathrm{O}_{2}$ to prevent oxidative stress.

\section{Tissue preparation}

WT and Prx $~^{-1-}$ mice at 15 months of age were sacrificed under anesthesia administered by intraperitoneal injection of pentobarbital sodium (50 mg/kg body weight). For SA- $\beta$-gal 
histochemistry, multiple tissue types were frozen in liquid nitrogen, and embedded in Optimal Cutting Temperature (OCT) compound (Tissue-Tek). After air drying for $30 \mathrm{~min}$, sections were fixed in $1 \%$ formalin for $1 \mathrm{~min}$, washed in PBS, dried, and stored at $-80^{\circ} \mathrm{C}$ until used for SA- $\beta$-gal staining.

\section{Western blot analysis and antibodies}

Cells harvested after treatment were lysed in RIPA buffer and subjected to western blot analysis as described previously (23). Antibodies were obtained from Prx I (Abfrontier); PCNA (DakoCytomation); Cyclin D1 (Cell Signaling Technology); p16 ${ }^{\text {INK4a }}$ and p21 $1^{\text {WAF1/Cip1 }}$ (Santa Cruz); $\beta$-actin (Sigma-Aldrich).

\section{Adenovirus production for Prx I}

Recombinant replication-deficient adenoviruses were used in this study. Adenovirus containing Prx I cDNA was a kind gift from Dr. Sang Won Kang (Ewha Womans University, Seoul, Korea), Large-scale amplification of the adenovirus was performed as previously described (34). In brief, HEK 293 cells were transfected with adenoviral vector (multiplicity of infection $=2$ ), and the replicated virus particles were concentrated by ultracentrifugation with a $\mathrm{CsCl}$ gradient. Viral titers were determined with a TCD50 assay (Adeno-Quest). Purified and concentrated adenovirus particles with titers ranging from $10^{9}$ to $10^{11} \mathrm{PFU} / \mathrm{ml}$ were suspended in $10 \mathrm{mM}$ Tris- $\mathrm{HCl}$ ( $\left.\mathrm{pH} 8.0\right), 2$ $\mathrm{mM} \mathrm{MgCl} 2$, and $5 \%$ sucrose. For in vitro infection with adenovirus, MEFs were plated at a density of $1 \times 10^{6}$ cells per well in 6-well cell culture plates (Corning) with DMEM plus $2 \%$ FBS containing the recombinant adenovirus at a concentration of 200 plaque-forming units (PFU) per cell as previously described $(36,37)$.

\section{Quantitative Real-time PCR analysis}

Total RNA was isolated from WT and Prx $\left.\right|^{-1-}$ MEFs at each passage using TRIZOL (Invitrogen) according to the manufacturer's instructions. For cDNA synthesis, $1 \mu \mathrm{g}$ of total RNA was used in a $20 \mu \mathrm{l}$ reaction mixture constituted using Maxime RT PreMix kit (Intron Biotechnology), and cDNA synthesized with oligo (dT) primers with the first-strand cDNA Synthesis kit (Toyobo) was mixed with the SYBR Premix Ex Taq (TaKaRa) and sets of gene-specific primers. Prx I (NM_011034.4) forward: 5'-tacgactagtccaggccttcc-3' reverse: 5'-gtccagtgctcacttctgctt-3'; Cyclin D1 (NM_007631.2) forward: 5'-gcaagcatgcacagacctt-3' reverse: $5^{\prime}$-gttgtgcggtagcaggaga-3'; p16 ${ }^{\text {INK4a }}$ (NM_001040654.1) forward: 5'-gtgtgcatgacgtgcggg-3'; reverse: $5^{\prime}$-acgtgaacgttgcccat cat-3'; p21 ${ }^{\text {WAF1/Cip1 }}$ (NM_007669.5) forward: 5'-gtggggtgaggagg agcatg-3' reverse: $5^{\prime}$-tgtgcggaacaggtcggaca-3'; $\beta$-actin (NM 007393.5) forward: 5'-cactgtcgagtcgcgtcc-3'; reverse: $5^{\prime}$-cgcag cgatatcgtcatcca- $3^{\prime}$. The resulting mixture was subjected to real-time RT-PCR quantification with the Mx QPCR Systems (Agilent). Primers for PCR were designed using the Primer3 software program. The specificity of primers was verified by BLAST analysis of the mouse and human genome, visualized by RT-PCR products after agarose gel electrophoresis, and analyzed by the melting point of the PCR products.

\section{Statistical analyses}

Experimental differences were tested for statistical significance using ANOVA and Student's t test on SigmaPlot 12.3 software. $P$ value of $<0.05$ was considered to be significant.

\section{ACKNOWLEDGEMENTS}

This study was supported by the partially from the R\&D Convergence Program (CAP-15-03-KRIBB) of NST (National Research Council of Science \& Technology), the KRIBB Research Initiative Programs (KGM4251723), and Bio \& Medical Technology Development Program of the NRF funded by the Korean government, MSIP (NRF-2012M3A9B6055362) of Republic of Korea.

\section{CONFLICTS OF INTEREST}

The authors have no conflicting interests.

\section{REFERENCES}

1. Schmitt CA, Fridman JS, Yang M et al (2002) A senescence program controlled by $\mathrm{p} 53$ and p16INK4a contributes to the outcome of cancer therapy. Cell 109, 335-346

2. Sharpless NE and DePinho RA (2002) p53: good cop/bad cop. Cell 110, 9-12

3. Moiseeva O, Bourdeau V, Roux A, Deschenes-Simard X and Ferbeyre G (2009) Mitochondrial dysfunction contributes to oncogene-induced senescence. Mol Cell Biol 29, 4495-4507

4. Barascu A, Le Chalony C, Pennarun G et al (2012) Oxidative stress induces an ATM-independent senescence pathway through p38 MAPK-mediated lamin B1 accumulation. EMBO J 31, 1080-1094

5. Frippiat C, Chen QM, Zdanov S, Magalhaes JP, Remacle J and Toussaint $\mathrm{O}$ (2001) Subcytotoxic $\mathrm{H} 2 \mathrm{O} 2$ stress triggers a release of transforming growth factor-beta 1, which induces biomarkers of cellular senescence of human diploid fibroblasts. J Biol Chem 276, 2531-2537

6. Parrinello S, Samper E, Krtolica A, Goldstein J, Melov S and Campisi J (2003) Oxygen sensitivity severely limits the replicative lifespan of murine fibroblasts. Nat Cell Biol 5, 741-747

7. Smirnov A, Panatta E, Lena A et al (2016) FOXM1 regulates proliferation, senescence and oxidative stress in keratinocytes and cancer cells. Aging (Albany NY) 8, 1384-1397

8. Labunskyy VM and Gladyshev VN (2013) Role of reactive oxygen species-mediated signaling in aging. Antioxid Redox Signal 19, 1362-1372

9. Ben-Porath $I$ and Weinberg RA (2005) The signals and pathways activating cellular senescence. Int J Biochem Cell Biol 37, 961-976

10. Kim TR, Lee HM, Lee SY et al (2010) SM22alpha-induced activation of p16INK4a/retinoblastoma pathway promotes 
cellular senescence caused by a subclinical dose of gamma-radiation and doxorubicin in HepG2 cells. Biochem Biophys Res Commun 400, 100-105

11. Ishii T, Yamada M, Sato $H$ et al (1993) Cloning and characterization of a 23-kDa stress-induced mouse peritoneal macrophage protein. J Biol Chem 268, 18633-18636

12. Park YH, Kim SU, Kwon TH et al (2016) Peroxiredoxin II promotes hepatic tumorigenesis through cooperation with Ras/Forkhead box M1 signaling pathway. Oncogene 35, 3503-3513

13. Przedborski S (2007) Peroxiredoxin-2 links Cdk5 to neurodegeneration. Nat Med 13, 907-909

14. Yang HY and Lee TH (2015) Antioxidant enzymes as redox-based biomarkers: a brief review. BMB Rep 48, 200-208

15. Han YH, Kim HS, Kim JM, Kim SK, Yu DY and Moon EY (2005) Inhibitory role of peroxiredoxin II (Prx II) on cellular senescence. FEBS Lett 579, 4897-4902

16. Immenschuh $\mathrm{S}$ and Baumgart-Vogt $\mathrm{E}$ (2005) Peroxiredoxins, oxidative stress, and cell proliferation. Antioxid Redox Signal 7, 768-777

17. Parmigiani RB, Xu WS, Venta-Perez G et al (2008) HDAC6 is a specific deacetylase of peroxiredoxins and is involved in redox regulation. Proc Natl Acad Sci U S A $105,9633-9638$

18. Kuilman T, Michaloglou C, Mooi WJ and Peeper DS (2010) The essence of senescence. Genes Dev 24, 2463-2479

19. Chen J, Huang X, Halicka D et al (2006) Contribution of p16INK4a and p21CIP1 pathways to induction of premature senescence of human endothelial cells: permissive role of p53. Am J Physiol Heart Circ Physiol 290, H1575-1586

20. Blander $G$, de Oliveira RM, Conboy CM, Haigis $M$ and Guarente L (2003) Superoxide dismutase 1 knock-down induces senescence in human fibroblasts. J Biol Chem 278, 38966-38969

21. de Haan JB, Bladier C, Lotfi-Miri M et al (2004) Fibroblasts derived from Gpx1 knockout mice display senescent-like features and are susceptible to $\mathrm{H} 2 \mathrm{O} 2$-mediated cell death. Free Radic Biol Med 36, 53-64

22. Volonte D and Galbiati F (2009) Inhibition of thioredoxin reductase 1 by caveolin 1 promotes stress-induced premature senescence. EMBO Rep 10, 1334-1340

23. Han YH, Kwon JH, Yu DY and Moon EY (2006) Inhibitory effect of peroxiredoxin II (Prx II) on Ras-ERK-NFkappaB pathway in mouse embryonic fibroblast (MEF) senescence. Free Radic Res 40, 1182-1189

24. Egler RA, Fernandes E, Rothermund $\mathrm{K}$ et al (2005) Regulation of reactive oxygen species, DNA damage, and c-Myc function by peroxiredoxin 1 . Oncogene $24,8038-8050$
25. Yang DG, Liu L and Zheng XY (2008) Cyclin-dependent kinase inhibitor p16(INK4a) and telomerase may comodulate endothelial progenitor cells senescence. Ageing Res Rev 7, 137-146

26. Turner-Ivey B, Manevich Y, Schulte J et al (2013) Role for $\operatorname{Prdx} 1$ as a specific sensor in redox-regulated senescence in breast cancer. Oncogene 32, 5302-5314

27. Campisi J (2005) Senescent cells, tumor suppression, and organismal aging: good citizens, bad neighbors. Cell 120, 513-522

28. Ko A, Han SY and Song J (2016) Dynamics of ARF regulation that control senescence and cancer. BMB Rep 49, 598-606

29. Krtolica A, Parrinello S, Lockett S, Desprez PY and Campisi J (2001) Senescent fibroblasts promote epithelial cell growth and tumorigenesis: a link between cancer and aging. Proc Natl Acad Sci U S A 98, 12072-12077

30. Lawrenson K, Grun B, Benjamin E, Jacobs IJ, Dafou D and Gayther SA (2010) Senescent fibroblasts promote neoplastic transformation of partially transformed ovarian epithelial cells in a three-dimensional model of early stage ovarian cancer. Neoplasia 12, 317-325

31. Romagosa C, Simonetti S, Lopez-Vicente L et al (2011) p16(Ink4a) overexpression in cancer: a tumor suppressor gene associated with senescence and high-grade tumors. Oncogene 30, 2087-2097

32. Collado M and Serrano M (2010) Senescence in tumours: evidence from mice and humans. Nat Rev Cancer 10, 51-57

33. Gorgoulis VG and Halazonetis TD (2010) Oncogeneinduced senescence: the bright and dark side of the response. Curr Opin Cell Biol 22, 816-827

34. Park YH, Kim SU, Lee BK et al (2013) Prx I suppresses K-ras-driven lung tumorigenesis by opposing redox-sensitive ERK/cyclin D1 pathway. Antioxid Redox Signal 19, 482-496

35. Cao J, Schulte J, Knight A et al (2009) Prdx1 inhibits tumorigenesis via regulating PTEN/AKT activity. EMBO J 28, 1505-1517

36. Zhu J, Grace M, Casale J et al (1999) Characterization of replication-competent adenovirus isolates from large-scale production of a recombinant adenoviral vector. Hum Gene Ther 10, 113-121

37. Chiche JD, Schlutsmeyer SM, Bloch DB et al (1998) Adenovirus-mediated gene transfer of cGMP-dependent protein kinase increases the sensitivity of cultured vascular smooth muscle cells to the antiproliferative and pro-apoptotic effects of nitric oxide/cGMP. J Biol Chem 273, 34263-34271 